\title{
ANALISIS LOGAM BERAT DI KEMASAN KALENG
}

\author{
Oleh : \\ Wildan Wibawa Perdana \\ Teknologi Pangan Universitas Al-Ghifari \\ wildan.w.perdana@gmail.com / wildan.w.perdana@unfari.ac.id
}

\begin{abstract}
Abstrak
Minuman yang dikemas oleh kaleng dapat terkontaminasi logam berat yang berasal dari komponen kaleng. Kontaminasi logam berat tersebut akan berbahaya bila masuk kedalam metabolism tubuh dalam jumlah yang melebihi ambang batas yang telah ditetapkan oleh BSN dan BPOM. Penelitian ini dilakukan untuk menganalisis Timbal $(\mathrm{Pb})$ dan Timah (Sn), dalam minuman kaleng yang terdiri dari minuman karbonasi, susu dan sari buah dengan masa simpan yang berbeda dan pengambilan sampel dilakukan di dua lokasi berbeda yaitu pasar modern dan pasar tradisional, dengan tujuan agar dapat membandingkan perbedaan pada pasar modern dan pada pasar tradisional. Serapan logam diukur dengan menggunakan spektofotometri serapan atom (SSA) pada gelombang yang spesifik. Penelitian menunjukan bahwa Timbal $(\mathrm{Pb})$ terkandung pada semua sampel dengan jumlah yang bervariasi antara $0,1468 \mathrm{mg} / \mathrm{kg} ; 0,1545 \mathrm{mg} / \mathrm{kg}$; $0,1556 \mathrm{mg} / \mathrm{kg} ; 0,1822 \mathrm{mg} \cdot \mathrm{kg} ; 0,1932 \mathrm{mg} / \mathrm{kg}$ dan $0,3692 \mathrm{mg} / \mathrm{kg}$. semakin lama masa penyimpanan, suhu penyimpanan yang tidak sesuai dengan jenis minuman dan perlakuan penyimpanan yang kurang baik semakin besar pula migrasi logam berat pada minuman didalamnya. Kadar logamTimah (Sn) pada tiga jenis minuman bervariasi antara 22,38 $\mathrm{mg} / \mathrm{kg} ; 27,81 \mathrm{mg} / \mathrm{kg} ; 42,39 \mathrm{mg} / \mathrm{kg} ; 45,12 \mathrm{mg} / \mathrm{kg} ; 45,64 \mathrm{mg} / \mathrm{kg}$; dan $60,42 \mathrm{mg} / \mathrm{kg}$. dari semua jenis minuman yang telah dianalis untuk cemaran logam $\mathrm{Pb}$ dan $\mathrm{Sn}$ tidak ada yang melebihi batas maksimum cemaran yang telah di tetap kan oleh Badan Standarisasi Nasional dan Badan Pengawas Obat dan Makanan, tetapi pada cemaran logam $\mathrm{Pb}$ ada yang mendekati batas maksimum.
\end{abstract}

Kata kunci : Minuman Kemasan Kaleng, SSA, Timbal dan Timah.

\begin{abstract}
Drinks packed with cans can be contaminated with heavy weavers that are comprised of canned components. Contamination of these acts will be dangerous to include in body metabolism in a number that exceeds the limits established by BSN and BPOM. The research is carried out to analyze Thimbal (Pb) and Timah $(S n)$, in the container of aluminum containers, the fruit juice and the different shrimp stores are taken in the dual allocation in the modern market and the traditional market. The absorption of the metal is measured by using an atomic photopometric (SSA) spectra of specific waves. The study showed that the Lead (Pb) was contained in a number of samples varying between $0.1468 \mathrm{mg} / \mathrm{kg} ; 0.1545 \mathrm{mg}$ / kg; $0.1556 \mathrm{mg} / \mathrm{kg} ; 0.1822$ storage with a type of drink and poorer storage practices also greater migrations of polyaddedaluminas. The thickness of the mineral content of the Tefah (Sn) of the various liquors varies between $22.38 \mathrm{mg} / \mathrm{kg} ; 27.81 \mathrm{mg} / \mathrm{kg} ; 42.39 \mathrm{mg} / \mathrm{kg} ; 45.12 \mathrm{mg} / \mathrm{kg} ; 45.64 \mathrm{mg} /$ $\mathrm{kg} ;$ and $60.42 \mathrm{mg} / \mathrm{kg}$. from all types of drinks that have been analyzed for contamination of the media. and Nothing exceeds the maximum number of contaminants that have been set by the National Standardization Standard and Consumed Consumers and Meals, but padographic loggers Bas closer to the maximum limit.
\end{abstract}

Keywords: Drinks packed, $A A S, P b$ and $S n$.

ANALISIS LOGAM
KEMASAN KALENG




\section{PENDAHULUAN}

Perkembangan bisnis di era globalisasi dunia cukup signifikan untuk menguasai pasar. Era globalisasi ini juga ditunjang dengan semakin pesatnya perkembangan teknologi informasi dan komunikasi sehingga dapat memudahkan semua orang dibelahan dunia bisa terhubung satu dengan yang lainnya tanpa adanya hambatan, hal ini juga disebut dengan istilah "dunia tanpa batas".

Hal tersebut membuka jalur pesaingan yang semakin kompetitif pada produk-produk minuman dan makanan dalam kemasan khususnya, perusahaan harus melakukan strategistrategi dan inovasi dalam memenangkan persaingan. Industri minuman mempunyai prospek yang cukup baik untuk berkembang sehingga banyak perusahaan yang berlomba dalam industri ini.

Kemasan kaleng merupakan kemasan yang mendominasi pasaran saat ini, konsumen memilih produk minuman atau makanan yang praktris, selain praktis kemasan kaleng mudah dijumpai di pasaran juga harganya relative terjangkau. Banyaknya penggunaan kemasan kaleng pada produk makanan dan minuman menjadi khawatiran, hal ini ditakutkan adanya pencemaran logam berat terhadap makanan atau minuman di didalamnya yang diakibatkan oleh faktor-faktor yang dapat mengakibatkan migrasinya logam berat dalam kaleng terhadap makanan atau minuman didalamnya.

Terlepas dari pertumbuhan yang masih rentan, industri minuman ringan menyediakan potensi yang sangat besar. Sebab Indonesia, sebagai negara dengan lebih dari 250 juta konsumen, lebih dari $25 \%$ (persen) merupakan usia produktif yang menjanjikan tak hanya di kelas menengah, tapi juga menengah ke bawah yang dapat menyediakan potensi pertumbuhan pasar konsumsi .Data BPS 2013 menunjukkan bahwa konsumen Indonesia membelanjakan 2\% (persen) belanja bulanan mereka untuk minuman (Trionio,2013).

$$
\text { Identifikasi }
$$

permasalahan tersebut yaitu apakah logam berat (Pb dan Sn) bermigrasi terhadap minuman kaleng didalamnya dan manakah logam berat $(\mathrm{Pb}$ dan $\mathrm{Sn})$ yang paling banyak terkandung pada minuman serta kaleng sari buah, susu, dan karbonasi. Sedangkan maksud dan tujuan merupakan untuk mengetahui ada atau tidaknya kandungan logam berat timah (Sn) dan timbal $(\mathrm{Pb})$ dan mengetahui besarnya kandungan logam berat ( $\mathrm{Pb}$ dan $\mathrm{Sn}$ ) pada minuman kaleng. Manfaat penelitian untuk mengetahui kandungan logam berat ( $\mathrm{Pb}$ dan $\mathrm{Sn}$ ) pada minuman berkarbonasi, sari buah, dan susu, berapa kadar logam berat ( $\mathrm{Pb}$ dan $\mathrm{Sn}$ ) yang terdapat pada minuman kaleng dan memberikan informasi kepada masyarakat ataupun penelitian guna penelitian berikutnya.

\section{Kerangka Pemikiran}

Kerusakan kemasan minuman dapat menyebabkan efek yang berbahaya seperti keracunan, salah satu kerusakan yang dapat dilihat yaitu, kerusakan fisik pada umumnya tidak membahayakan konsumen secara langsung, misalnya terjadinya kerusakan karena benturan yang keras.

Selanjutnya kerusakan kimia berupa kerusakan yang terjadi karena reaksi kimia yang berlangsung di dalam bahan makanan seperti penurunan $\mathrm{pH}$, reaksi reduksi dan oksidasi. Hal tersebut disebabkan karena penggunaan jenis wadah kaleng yang kurang sesuai untuk jenis makanan/minuman tertentu sehingga memicu terjadinya reaksi kimia antara kaleng dengan makanan/minuman. Kerusakan kimia yang sering terjadi pada makanan/minuman kaleng antara lain kaleng terjadi pengaratan pada kaleng, terbentuknya warna hitam, pemudaran warna kaleng serta kaleng menjadi kembung akibat terbentuknya gas hidrogen.

Kerusakan mikrobiologi pada minuman kaleng dibedakan atas dua kelompok, yaitu kaleng menjadi 
kembung akibat Pembentukan gas, terutama hidrogen (H2) dan Pembentukan gas, terutama hidrogen (H2) dan karbon dioksida (CO2) yang disebabkan oleh pertumbuhan berbagai spesies bakteri pembentuk spora yang bersifat anaerobik yang tergolong Clostridium, termasuk C. botulinum yang memproduksi racun yang sangat mematikan. Kaleng tetap terlihat normal yaitu tidak kembung karena Tidak terbentuk gas,kerusakan semacam ini adalah Busuk asam yang disebabkan oleh pembentukan asam oleh beberapa bakteri pembentuk spora yang tergolong Bacillus, Busuk sulfida yang disebabkan oleh pertumbuhan bakteri pembentuk spora yang memecah protein dan menghasilkan hidrogen sulfida (H2S) sehingga makanan kaleng menjadi busuk dan berwarna hitam karena reaksi antara sulfida dengan besi.

Pada minuman kaleng, masalah yang sering dijumpai dalam kemasan kaleng itu sendiri adalah adanya korosi, faktor yang mempengaruhi besarnya korosi pada kaleng bagian dalam yaitu, tingkat sisa oksigen dalam makanan, Adanya akselatorkorosi seperti nitrat dan senyawa sulfur lainnya, $\mathrm{pH}$ minuman dalam kaleng, Suhu dan lama penyimpanan, dan jenis kaleng dan lapisan penahan korosi.

Menurut penelitian yang telah dilakukan untuk penentuan kandunagn logam $\mathrm{Cu}, \mathrm{Pb}, \mathrm{Na}, \mathrm{Zn}, \mathrm{Fe}$, dan $\mathrm{Mg}$ dalam minuman bir kaleng yang dijual di pasaran dengan mengunakan metoda destruksi basah menggunakan campuran $\mathrm{HNO} 3$ dan $\mathrm{H} 2 \mathrm{O} 2$ dan kadar logam ditentukan dengan spektrofotometri serapan atom (SSA). Menunjukkan hasil Kandungan tembaga $(\mathrm{Cu})$, timbal $(\mathrm{Pb})$ dan natrium $(\mathrm{Na})$ tidak melampaui kesehatan, kandungan logam seng ( $\mathrm{Zn}$ ) telah melewati ambang batas cemaran logam berat dalam minuman bir yang ditetapkan oleh Ditjen POM. Sedangkan besi (Fe) dan magnesium $(\mathrm{Mg})$ melewati batas maksimum ketentuan kualitas air minum yang ditetapkan oleh peraturan Mentri Kesehatan RI. (Zilfa, 2008).

\section{Hipotesis Penelitian}

Berdasarkan pemikiran diatas bahwa diduga pada minuman kaleng dapat terjadi migrasi kandungan logam berat (Pb dan $\mathrm{Sn}$ ) pada kemasan kaleng kedalam minuman didalamnya.

\section{BAHAN DAN METODE PENELITIAN}

\section{Waktu dan Tempat}

Penelitian ini akan dilakukan di Lab. Universitas Padjadjaranpada bulan Agustus - September 2018 yang bertempat di Universitas Padjadjaranjl. Raya Bandung-Sumedang $\mathrm{Km}$ 21, Jatinangor, Bandung, Jawa Barat 40600 Indonesia.

\section{Bahan dan Alat Penelitian}

Untuk mendapatkan hasil yang maksimal dari segi kualitas dan kuantitas, bahan dan alat penelitian harus diperhatikan. Adapun bahan dan alat yang digunakan dalam penelitian ini yaitu meliputi bahan produk dan bahan analisis, serta alat analisis. Bahan dan alat untuk menganalisis logam berat yang terdiri dari $\mathrm{Pb}$ dan $\mathrm{Sn}$ pada sample minuman yang terdiri dari minuman susu, minuman karbonasi, dan minuman sari buah memerlukan bahan penelitian dan alat penelitian sebagai berikut:

\section{Bahan Penelitian}

Bahan produk yang digunakan dalam penelitian ini yaitu : sample minuman karbonasi, sample minuman susu, dan sample minuman sari buah. Bahan analisis yang digunakan dalam penelitian ini yaitu : Serbuk standar $\mathrm{Pb}$ (NO3)2 (Merck), serbuk SnCl2.2H2O (Merck), larutan HNO3 pekat (Merck), larutan $\mathrm{HCl}$ pekat (Merck), dan aqua demineralisata.

\section{Alat Penelitian}

Alat-alat yang digunakan pada penelitian ini adalah corong, gelas beaker, hot plate, kertas saring, kurs porselen, labu digesti, labu ukur $100 \mathrm{ml}$ dan $250 \mathrm{ml}$, pipet volume, spektrofotometri serapan atom (SSA), tanur, dan timbangan analitik. 


\section{Metode penelitian}

Metode penelitian yang digunakan meliputi : (1) Rancangan Perlakuan, (2) Rancangan Percobaan, (3) Rancangan Respon

\section{Rancangan Perlakuan}

Pada penelitian ini dilakukan analisis logam berat dengan perlakuan minuman yang berbeda, serta pada lokasi yang berbeda. Hal ini ditujukan agar peneliti dapat membandingkan kadar logam berat pada sample minuman dan lokasi yang berbeda. Kemungkinan kadar logam berat pada lokasi dan sample minuman yang berbeda akan mendapatkan hasil yang berbeda.

$$
\text { Penentuan lokasi untuk }
$$
pengambilan sample dilakukan di dua lokasi yang berbeda yaitu pasar Modern dan pasar Tradisional. Penentuan lokasi

Tabel 1. Jenis sampel minuman.

\begin{tabular}{|c|c|c|c|}
\hline \multirow[b]{2}{*}{$\begin{array}{c}\text { Pasar modern/Pasar } \\
\text { tradisional }\end{array}$} & \multicolumn{3}{|c|}{ Sample } \\
\hline & $\begin{array}{l}\text { Minuman } \\
\text { karbonasi }\end{array}$ & Minuman susu & $\begin{array}{c}\text { Minuman sari } \\
\text { buah }\end{array}$ \\
\hline Pasar modern & a1 & $\mathrm{b} 2$ & c3 \\
\hline Pasar tradisional & $\mathrm{a} 2$ & $\mathrm{~b} 2$ & c3 \\
\hline
\end{tabular}

Pada penelitian ini sample minuman didapatkan di lokasi yang berbeda diantaranya pasar modern dan pasar tradisional dengan tujuan agar hasil pengamatan terlihat perbedaannya.

\section{Rancangan Percobaan}

Pada penelitian ini dilakukan percobaan analisis logam berat dengan pengambilan sample di pasar modern dan tradisional. Sample diperoleh dari dua lokasi berbeda dengan pengamatan logam berat (Pb dan $\mathrm{Sn})$.

Dari hasil Survey dengan metode pengumpulan data primer yaitu memberikan pertanyaan-pertanyaan kepada responden individu. mengumpulkan informasi dari kelompok responden yang mewakili sebuah populasi.

Penentuan lokasi merupakan salah satu bagian terpenting pada penelitian ini, hal tersebut dikarenakan lokasi menjadi tempat dimana sample akan diambil. Perbedaan lokasipun akan menjadi salah satu faktor perbedaan hasil ini didasarkan atas perlakuan penyimpanan pada lokasi yang berbeda, perbedaan dapat dilihat dari perlakuan penyimpanan. Pasar modern biasanya disimpan di gudang dengan suhu ruang yang disesuaikan dengan kondisi minuman tersebut dan tidak terpapar langsung oleh sinar matahari. Pasar tradisional biasanya tidak terlalu memperhatikan kondisi suhu ruang dan biasanya minuman terebut terkena paparan sinar matahari.

Berbagai jenis minuman dapat ditemukan di pasar modern ataupun tradisional, jenis minuman tersebut beraneka ragam diantaranya minuman kaleng jenis susu, karbonasi, dan sari buah. Adapun perlakuan penelitian / perbandingan sampel minuman pada 2 tempat yang berbeda yang dilakukan oleh peneliti. : penelitian ini. Sample merupakan bagian dari populasi yang ingin diteliti, dipandang sebagai sebagai pendugaan terhadap populsi, namun bukan populasi itu sendiri. Sample dianggap sebagai perwakilandari populasi yang hasilnya mewakili keseluruhan gejala yang diamati.

Sample yang digunakan pada penelitian ini yaitu, minuman susu, minuman karbonasi, dan minuman sari buah. Penentuan sample ini didasarkan atas perlakuan bahan minuman yang berbeda, sehingga kemungkinan kadar logam berat yang terkandung pada tiga jenis minuman tersebut berbeda.

Prosedur penelitian untuk penentuan sample yaitu dengan metode Spektrofotometri Serapan Atom (SSA). Sample kemudian dianalisis di laboratorium dengan menggunakan alat Spektrofotometri Serapan Atom (SSA). Parameter yang diamati dalam penelitin ini yaitu analisis logam berat $\mathrm{Pb}, \mathrm{Mg}$, As (SNI 2354.5:2011) pada minuman kaleng. Pada penelitian ini, peneliti menganalisis 
dua jenis logam berat diantaranya $\mathrm{Pb}$ dan Sn. Logam berat tersebut kemungkinan besar ada pada sampel minu man.

Tujuannya adalah agar peneliti dapat memilih salah satu pilihan dari berbagai alternative kebijakan yang ada berdasarkan kriteria dan indikator yang telah ditetapkan.

Rancangan percobaan lainnya, dilakukan dengan cara menganalisis

Tabel.2 Tabel Rancangan Acak Kelompok(RAK).

\begin{tabular}{lcccc}
\hline \multirow{2}{*}{$\begin{array}{c}\text { Pasar modern/Pasar } \\
\text { tradisional }\end{array}$} & \multicolumn{2}{c}{$\begin{array}{c}\text { Minuman } \\
\text { karbonasi }\end{array}$} & Minuman susu & $\begin{array}{c}\text { Minuman sari } \\
\text { buah }\end{array}$ \\
\cline { 2 - 5 } Pasar modern & $\mathrm{a} 1$ & $\mathrm{~b} 2$ & $\mathrm{c} 3$ \\
Pasar tradisional & $\mathrm{a} 2$ & $\mathrm{~b} 2$ & $\mathrm{c} 3$ \\
\hline
\end{tabular}

Pengukuran Kadar Timbal dan Timah dalam sampel

Pengukuran kadar timbal dan timah dimulai dengan melakukan pengukuran larutan standar masingmasing logam. Pengukuran diawali oleh larutan standar dengan konsentrasi paling kecil, kemudian diteruskan hingga konsentrasi paling tinggi.

sampel minuman kemasan kaleng masingmasing sampel di analisis dengan pengulangan sebanyak dua kali. Rancangan percobaan ini dilakukan untuk mendapatkan hasilyang lebih maksimal, beriku tabel rancangan acak kelompokanalisis logam berat $\mathrm{Pb}$ dan $\mathrm{Sn}$ pad minuman kemasan kaleng.

Tabel. 3. Ketentuan alat SSA untuk pengukuran kadar timbal dan timah

\begin{tabular}{lll}
\hline \multicolumn{1}{c}{ Ketentuan } & Timbal $(\mathrm{Pb})$ & Timah $(\mathrm{Sn})$ \\
\hline Panjang gelombang & $283,3 \mathrm{~nm}$ & $286,3 \mathrm{~nm}$ \\
Kecepatan gas pembakar (asetilen) & $2,0 \mathrm{~L} /$ menit & $3,0 \mathrm{~L} /$ menit \\
Kecepatan oksidan (udara) & $15,0 \mathrm{~L} / \mathrm{menit}$ & $15,0 \mathrm{~L} / \mathrm{menit}$ \\
Tinggi burner & $7 \mathrm{~mm}$ & $9 \mathrm{~mm}$ \\
\hline
\end{tabular}

Sumber : Shimadzu, 2007

Pengukuran kandungan Logam Timbal dalam minuman kemasan kaleng dilakukan pada panjang gelombang 283,3 $\mathrm{nm} ; 286,3 \mathrm{~nm}$. Panjang gelombang tersebut merupakan panjang gelombang paling kuat menyerap garis untuk transisi elektronik dari tingkat dasar ke tingkat eksitasi. Bila atom tingkat energi dasar (ground state) diberi energi yang sesuai, maka energi tersebut akan diserap lalu atom akan terseksitasi ke tingkat energi yang lebih tinggi (exited state), sedangkan atom yang tidak stabil akan sebaliknya yaitu kembali ke tingkat energi dasar dengan melepas sejumlah energi dalam bentuk sinar panjang gelombang optimum untuk Timbal $(\mathrm{Pb})$ dan Timah (Sn) berturut-turut adalah : 283,3 $\mathrm{nm}$; $286,3 \mathrm{~nm}$.
Selanjutnya dilakukan pengukuran serapan sampel. Serapan sampel yang diperoleh dimasukan kedalam persmaan kurva kalibrasi sehingga diperoleh kadar sampel. Pengukuran dilakukan dengan menggunakan spektofotometri serapan atom (SSA) dengan ketentuan alat sebagai berikut : 
(Kiki Agus, Kiki Yulianti, Siti Hanggita, 2012).

\section{Deskripsi percobaan}

Deskripsi atau gambaran pada percobaan analisis logam berat $(\mathrm{Pb}$ dan
Sn) pada minuman kaleng di kota Bandung yang dilakukan dalam penelitian ini Adalah sebagai berikut :

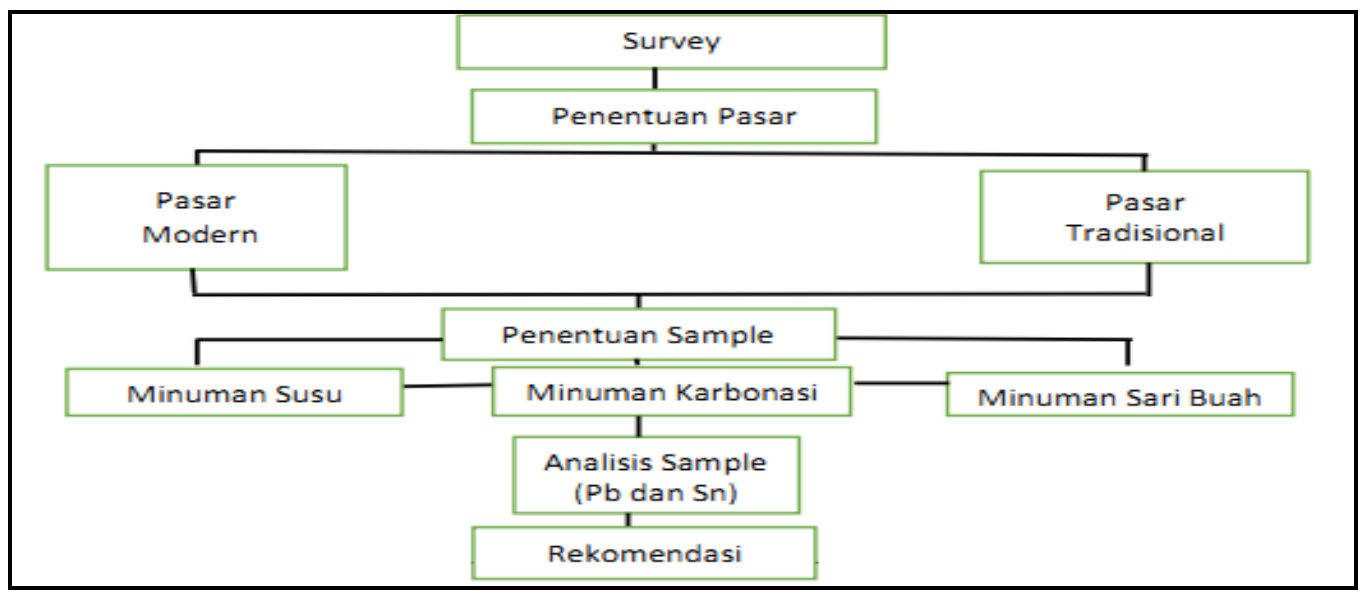

Gambar 1. Algoritma penelitian minuman kaleng.

\section{HASIL DAN PEMBAHASAN}

Penelitian ini dilakukan untuk menganalisis cemaran logam timbal dan timah dalam minuman kaleng yang terdiri dari minuman susu, karbonasi dan sari buah dengan lokasi pembelian yang berbeda dan masa simpan yang berbeda.berdasarkan hasil yang diperoleh, ditentukan kelayakan minuman dalam kaleng tersebut untuk dikonsumsi oleh masyarakat. Kelayakan ini mengacu pada batas maksimum cemaran logam berat dalam makanan yang tela ditetapkan oleh BPOM dan SNI.

Sampel yang digunakan adalah minuman kemasan kaleng yang dibeli dari dua lokasi berbeda yakni pasar modern dan pasar tradisional daerah kota Bandung. Sampel yang digunakan dipilih berdasarkan masa simpan yang berbeda yaitu, minuman kaleng dengan masa simpan baru (masa simpan kurang dari satu tahun) dan minuman kaleng dengan masa simpan lama (masa simpan lebih dari satu tahun).

Tabel 4. Tanggal produksi dan kadaluarsa sampel minuman kaleng.

\begin{tabular}{lll}
\hline \multicolumn{1}{c}{ Sample } & Tanggal Produksi & Tanggal kadaluarsa \\
\hline A1 & 20 September 2016 & 20 September 2019 \\
A2 & 16 Juni 2014 & 16 Juni 2017 \\
B1 & 19 Agustus 2016 & 19 Agustus 2019 \\
B2 & 7 Juli 2014 & 7 Juli 2018 \\
C1 & 14 April 2015 & 14 April 2018 \\
C2 & 1 Juli 2014 & 1 Juli 2018 \\
\hline
\end{tabular}

Menurut Laroussen dan Brown, 1997 dan Julianti dan Nurminah, 2006 Terdapatnya cemaran logam berat pada minuman kaleng bisa terjadi karena adanya migrasi logam-logam penyusun kaleng ke dalam produk, hal ini dapat disebabkan karena beberapa faktor, seperti $\mathrm{pH}$, waktu penyimpanan, suhu penyimpanan, Sisa oksigen dalam bahan pangan, dan beberapa factor yang berasal dari bahan kemas.
Sampel minuman kaleng yang digunakan yaitu tiga jenis minuman yang berbeda, dengan lokasi dan masa simpan yang berbeda. Perbedaaan masa simpan dapat dilihat apakah ada perbedaan kandungan logam dari ke tiga sampel dengan masa simpan yang berbeda. Menurut Laraussen dan Brown (1997), Dengan semakin lama makanan/minuman disimpan, maka semakin lama kontak antara makanan 
dengan wadah. Dengan demikian, semakin besar pula kemungkinan logam penyusun kaleng tersebut lepas dan mengkontaminasi makanan didalamnya.

\section{Timbal (Pb)}

Terdeteksi logam timbal pada semua sampel yang dianalisis dengan kadar yang berbeda dengan Rata-rata kadar yang terkandung di dalam minuman kemasan kaleng a1, a2, b1, b2, c1, dan c2 berturut-turut yaitu 0,1932 ; 0,$3692 ; 0,1468 ; 0,1545 ; 0,1822 ; 0,1556$. Menurut De Leon, "Kontaminasi logam timbal ini dapat terjadi karena timbal biasa digunakan untuk menyambung bagian tutup kaleng dengan bagian badan kaleng juga untuk menyambung bagian bawah kaleng dengan badan kaleng" (De Leon, 1995).

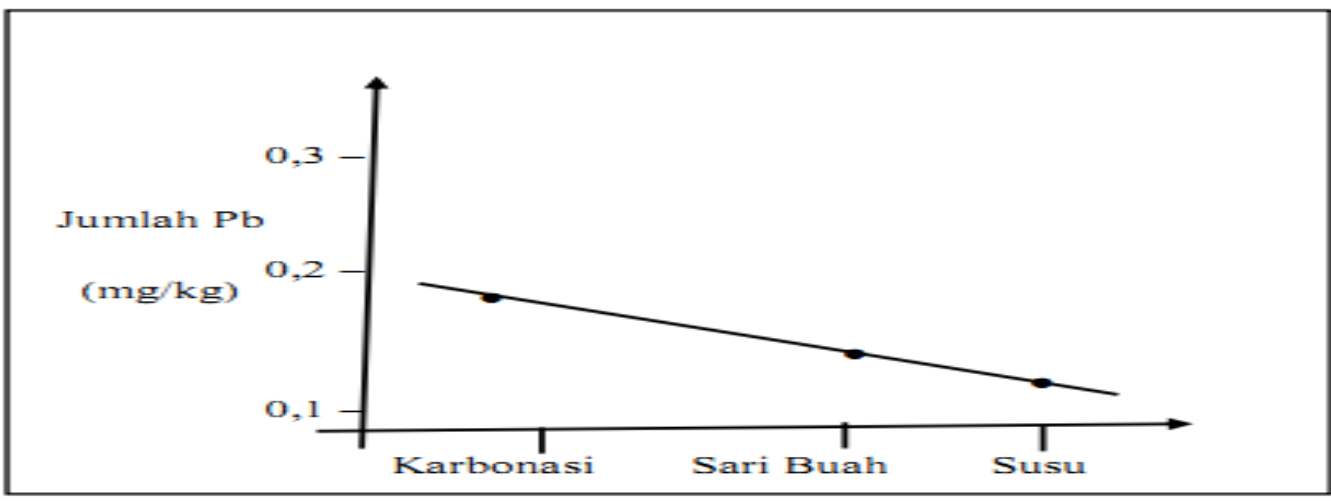

Gambar 2. Hasil Analisis kandungan Timbal (Pb) pada pasar Modern.

Hasil analisis kandungan timbal pada pasar modern dapat dilihat pada gambar.6 hasil menunjukan minuman kemasan kaleng jenis karbonasi memiliki kandungan logam timbal yang paling tinggi dibandingkan dengan dua jenis minuman lainnya yaitu minuman sari buah dan minuman susu. Hasil logam $\mathrm{Pb}$ pada minuman kemasan kaleng bervariasi dengan hasil analisis berturutturut adalah $0,1932 \mathrm{mg} / \mathrm{kg} ; 0,1822$ $\mathrm{mg} / \mathrm{kg} ; 0,1468 \mathrm{mg} / \mathrm{kg}$. jenis minuman karbonasi memiliki kadar logam $\mathrm{Pb}$ yang tinggi hal ini dikarenakan sifat minuman karbonasi yang dapat membentuk asam karbonat sehingga dapat membuat kaleng menjadi cepat korosi. Logam $\mathrm{Pb}$ terdapat pada semua jenis minuman tetapi tidak melebihi cemaran yang telah ditetapkan oleh BSN dan BPOM sehingga masih aman untuk dikonsumsi.

Menurut Vera (2011) hasil analisisnya menunjukan bahwa pada analisis logam berat $\mathrm{Pb}$ dan $\mathrm{Sn}$ pada buah lengkeng kemasan kaleng logam timbal terdeteksi pada semua sampel yang dianalisis dengan kadar yang berbedabeda. Rata-rata kadar Jumlah $\mathrm{Pb}$ $(\mathrm{mg} / \mathrm{kg})$ logam timbal yang terkandung didalam lengkeng A1, A2, A3, B1, B2, dan B3 berturut-turut adalah 0,4696 $\mathrm{mg} / \mathrm{kg} ; 0,4429 \mathrm{mg} / \mathrm{kg} ; 0,3415 \mathrm{mg} / \mathrm{kg}$; $0,3423 \mathrm{mg} / \mathrm{kg} ; 0,2323 \mathrm{mg} \cdot \mathrm{kg} ; 0,2067$ $\mathrm{mg} / \mathrm{kg}$.

Terdeteksi logam timbal di dalam buah lengkeng kemasan kaleng dikatakan sebagai kontaminasi makanan karena timbal merupakan logam yang berbahaya bagi tubuh kontaminasi logam timbal ini dapat terjadi karena timbal biasa digunakan untuk menyambung bagian bawah kaleng dengan badan kaleng. Pateri ini biasanya menggunakan campuran dari $90 \%$ timbal dan $10 \%$ timah.

Lepasnya logam timbal kedalam makanan ini dapat terjadi akibat dari masa penyimpanan karena semakin lama penyimpanan biasanya semakin lama kontak makanan didalam kemasan dengan kemasan kaleng itu sendiri, hal ini dibuktikan dengan penelitianpenelitian yang telah dilakukan hasil analisis dapat terlihat pada grafik cenderung menurun ini dapat diakibatkan karena lamanya masa simpan pada sampel dan jenis sampel yang berbeda. 


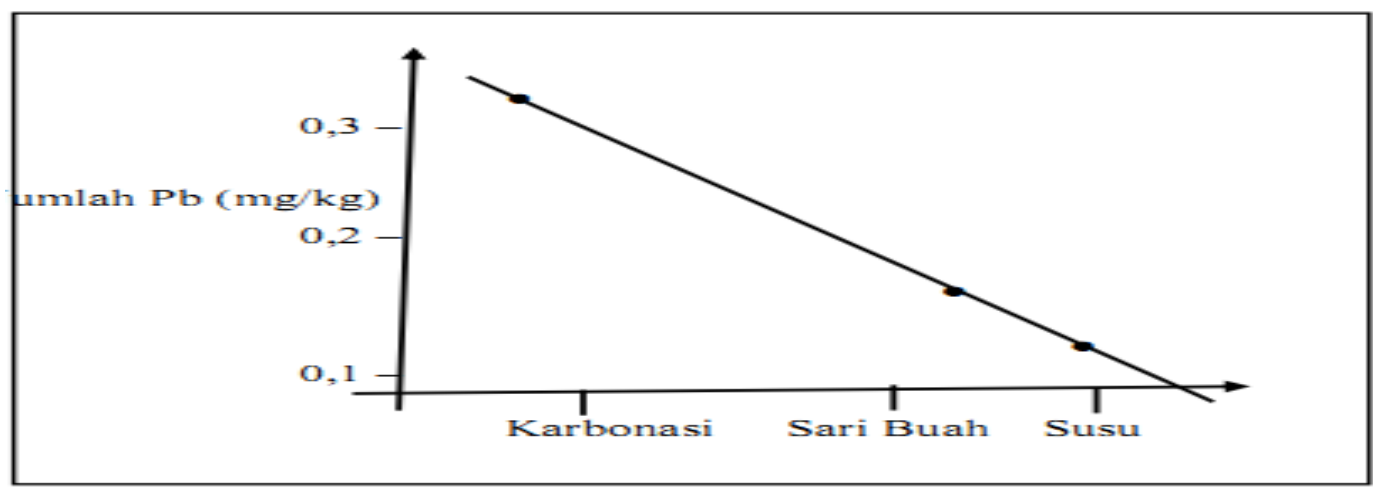

Gambar 3. Hasil Analisis kandungan Timbal (Pb) pada pasar Tradisional Jumlah $\mathrm{Pb}(\mathrm{mg} / \mathrm{kg})$.

Hasil analisis kandungan timbal pada pasar tradisional dapat dilihat pada gambar.7 hasil menunjukan minuman kemasan kaleng jenis karbonasi memiliki kandungan logam timbal yang paling tinggi dibandingkan dengan dua jenis minuman lainnya yaitu minuman sari buah dan minuman susu. Hasil logam $\mathrm{Pb}$ pada minuman kemasan kaleng bervariasi dengan hasil analisis berturut-turut adalah $0,3692 \mathrm{mg} / \mathrm{kg}$; $0,1556 \mathrm{mg} / \mathrm{kg} ; 0,1545 \mathrm{mg} / \mathrm{kg}$. jenis minuman karbonasi memiliki kadar logam $\mathrm{Pb}$ yang tinggi hal ini dikarenakan sifat minuman karbonasi yang dapat membentuk asam karbonat sehingga dapat membuat kaleng menja di cepat

Tabel 5. Kadar logam Pb.

\begin{tabular}{ccccc}
\hline \multirow{2}{*}{ No } & \multirow{2}{*}{ Sampel } & \multicolumn{3}{c}{ Uji Pb } \\
\cline { 3 - 5 } & & & $\mathbf{I}$ & $\mathbf{I I}$ \\
\hline 1 & $\mathrm{a} 1$ & 0,19 & 0,2 & \\
2 & $\mathrm{a} 2$ & 0,37 & 0,47 & \\
3 & $\mathrm{~b} 1$ & 0,15 & 0,24 & \\
4 & $\mathrm{~b} 2$ & 0,15 & 0,2 & \\
5 & $\mathrm{c} 1$ & 0,18 & 0,25 & \\
6 & $\mathrm{c} 2$ & 0,16 & 0,25 \\
\hline
\end{tabular}

\section{Timah (Sn)}

Logam timah terdeteksi pada semua sampel minuman kemasan kaleng baik yang didapat dari pasar modern atau pasar tradisional. Rata-rata kadar logam timah ynag terkandung di dalam minuman kaleng a1, a2, b1, b2, c1 dan c2 berturut-turut adalah $45,12 \mathrm{mg} / \mathrm{kg}$ ; 60,42 mg/kg ; 22,38 mg/kg ; 27,81 $\mathrm{mg} / \mathrm{kg} ; 45,65 \mathrm{mg} / \mathrm{kg} ; 42,39 \mathrm{mg} / \mathrm{kg}$.

Cemaran logam timah yang terdapat dalam minuman kemasan kaleng, baik minuman karbonasi, susu ataupun sari buah, berasal dari kaleng korosi. Logam $\mathrm{Pb}$ terdapat pada semua jenis minuman tetapi tidak melebihi cemaran yang telah ditetapkan oleh BSN dan BPOM sehingga masih aman untuk dikonsumsi, tetapi pada minuman karbonasi yang didapatkan di pasar tradisional mendekati batas maksimum yang telah ditetapkan.

\section{Rancangan Percobaan}

Analisis logam berat $\mathrm{Pb}$ pada penelitian ini dilakukan dengan cara rancangan acak lengkap yang dilakukan pengulangan sebanyak dua kali berikut adalah tabel analisis logam berat $\mathrm{Pb}$ pada minuman kemasan kaleng : yang digunakan sebagai wadah. Jenis kaleng yang sering digunakan untuk mengemas makanan atau minuman sering digunakan adalah timplate, yaitu kaleng yang terbuat dari baja dan dilapisi oleh timah putih dengan tujuan agar kaleng yang digunakan tidak cepat korosi. Kontaminasi timah pada minuman kaleng tersebut disebabkan karena larutannya lapisan timah pada bagian dalam kaleng kedalam produk larutnya logam timah kedalam produk dipengaruhi oleh lamanua masa simpan dan kondisi penyimpanan. 
Konsentrasinya dalam minuman dapat meningkat apabila kemasaman kaleng dibuka dan/atau disimpan dalam waktu yang lama.

Hasil penelitian yang dilakukan menunjukan bahwa minuman kemasan kaleng yang memiliki masa simpan yang baru (masa simpan kurang dari satu tahun) mengandung timah dengan kadar yang lebih rendah dibandingkan dengan minuman kemasan kaleng yang masa simpan lama (masa simpan lebih dari satu tahun). Atau mendekati tanggal kadaluarsa. Ke 3 jenis minuman kaleng yang diuji menunjukan hal yang serupa, yaitu kadar timah akan meningkat seiring dengan meningkatnya masa simpan minuman kaleng dalam kemasan kaleng.

Tiga jenis minuman kemasan kaleng yang terdiri dari minuman karbonasi, susu dan sari buah yang dianalisa memiliki kadar timah dibawah batas maksimum cemaran makanan yang telah ditetapkan oleh BSN dan BPOM pada tahun 2009, yaitu $250 \mathrm{mg} / \mathrm{kg}$, sehingga masih layak untuk dikonsumsi.

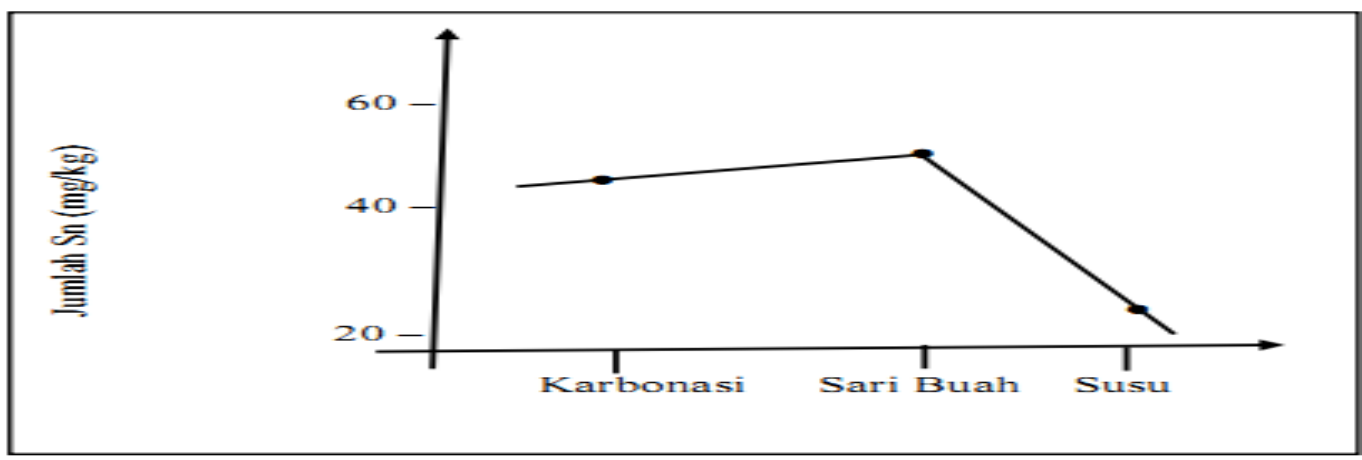

Gambar 4. Hasil Analisis kandungan Timah (Sn) pada pasar Modern.

Hasil analisis kandungan timah pada pasar modern dapat dilihat pada gambar.8 hasil menunjukan minuman kemasan kaleng jenis sari buah memiliki kandungan logam timah yang paling tinggi dibandingkan dengan dua jenis minuman lainnya yaitu minuman karbonasi dan minuman susu. Hasil logam Sn pada minuman kemasan kaleng bervariasi dengan hasil analisis berturut-turut adalah
$45,12 \mathrm{mg} / \mathrm{kg} \quad ; 45,65 \mathrm{mg} / \mathrm{kg} \quad ; \quad 22,38$ $\mathrm{mg} / \mathrm{kg}$. jenis minuman Sari buah memiliki kadar logam Sn yang tinggi dibandingkan dengan minuman jenis lainnya. Logam Sn terdapat pada semua jenis minuman tetapi tidak melebihi cemaran yang telah ditetapkan oleh BSN dan BPOM sehingga masih aman untuk dikonsumsi.

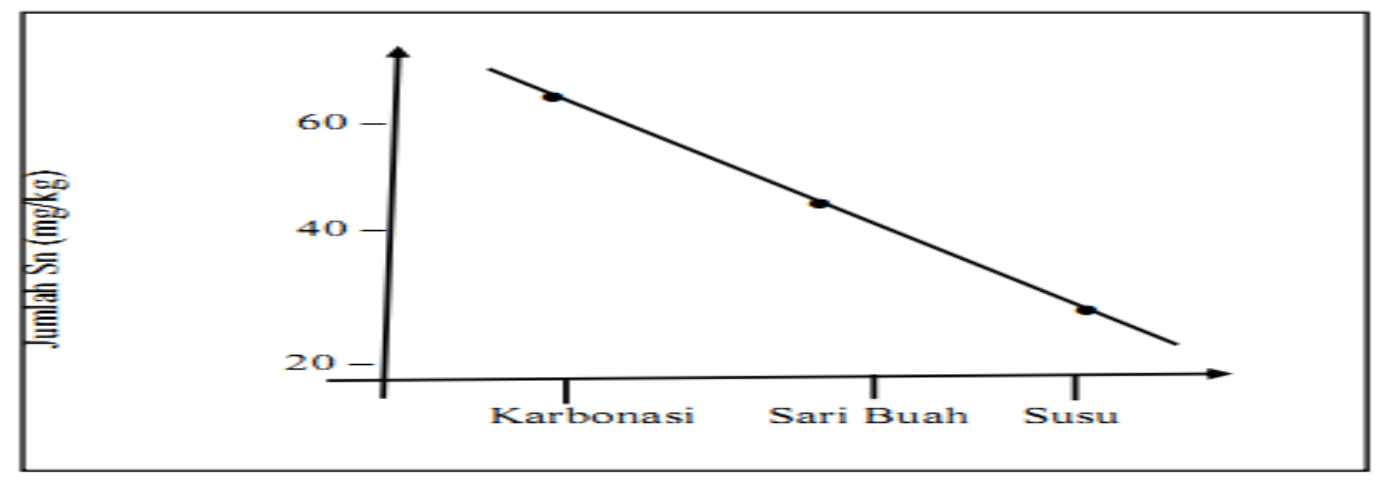

Gambar 5. Hasil Analisis kandungan Timah (Sn) pada pasar Tradisional.

Hasil analisis kandungan timah pada pasar tradisional dapat dilihat pada gambar.9 hasil menunjukan minuman kemasan kaleng jenis karbonasi memiliki kandungan logam timah yang paling tinggi dibandingkan dengan dua jenis minuman lainnya yaitu minuman sari buah dan minuman susu. Hasil logam Sn pada minuman kemasan kaleng bervariasi dengan hasil analisis 
berturut-turut adalah $60,42 \mathrm{mg} / \mathrm{kg}$; $42,39 \mathrm{mg} / \mathrm{kg} \quad ; \quad 27,81 \mathrm{mg} / \mathrm{kg}$. jenis minuman Karbonasi memiliki kadar logam Sn yang tinggi dibandingkan dengan minuman jenis lainnya. Logam Jumlah Sn $(\mathrm{mg} / \mathrm{kg})$ Sn terdapat pada semua jenis minuman tetapi tidak melebihi cemaran yang telah ditetapkan oleh BSN dan BPOM sehingga masih aman untuk dikonsumsi.

Menurut Vera (2011) hasil analisisnya menunjukan bahwa pada analisis logam berat $\mathrm{Pb}$ dan $\mathrm{Sn}$ pada buah lengkeng kemasan kaleng logam timah terdeteksi pada semua sampel yang dianalisis dengan kadar yang berbedabeda. Rata-rata kadar logam timbal yang terkandung didalam lengkeng $\mathrm{A} 1$, A2, A3, B1, B2, dan B3 berturut-turut adalah $343,7587 \mathrm{mg} / \mathrm{kg} ; 317,9589 \mathrm{mg} / \mathrm{kg}$ ; 40,9649 mg/fkg ; 282,5897 mg/kg ; $67,6616 \mathrm{mg} / \mathrm{kg} ; 45,1083 \mathrm{mg} / \mathrm{kg}$.

Kondisi dan lamanya suatu penyimpanan mempengaruhi larutnya logam timah kedalam produk. Semakin lama masa simpan semakin besar waktu kontak wadah dengan makanan sehingga kemungkinan migrasi timah semakin besar, Konsentrasinya dalam makanan dapat meningkat apabila kemasan kaleng dibuka dan/atau disimpan dalam waktu yang lama dan suhu tinggi (WHO,2005).

Analisis logam berat Sn pada penelitian ini dilakukan dengan cara rancangan acak lengkap yang dilakukan pengulangan sebanyak dua kali berikut adalah tabel analisis logam berat $\mathrm{Sn}$ pada minuman kemasan kaleng :

Tabel 6. Kadar logam Sn

\begin{tabular}{ccccc}
\hline \multirow{2}{*}{ No } & \multirow{2}{*}{ Sampel } & \multicolumn{3}{c}{ Uji Sn } \\
\cline { 3 - 5 } & & & I & II \\
\hline 1 & a1 & a2 & 45,12 & 46,98 \\
3 & b1 & 60,42 & 61,89 \\
4 & b2 & 22,38 & 24,25 \\
5 & c1 & 27,81 & 28,91 \\
6 & c2 & 45,65 & 46,92 \\
\end{tabular}

\section{KESIMPULAN}

1. Logam timbal $(\mathrm{Pb})$ dan timah $(\mathrm{Sn})$ terdeteksi pada semua jenis sampel minuman yang dianalis dengan kadar yang berbeda-beda, dan tidak melebihi batas yang telah ditetapkan oleh BSN dan BPOM.

2. Kadar logam Timbal $(\mathrm{Pb})$ pada sampel a1, a2, b1, b2, c1, dan c2 berturut-turut adalah $\quad 0,1932 \mathrm{mg} / \mathrm{kg} \quad ; \quad 0,3692$ $\mathrm{mg} / \mathrm{kg} \quad ; \quad 0,1468 \mathrm{mg} / \mathrm{kg} \quad ; \quad 0,1545$ mg.kg ; 0,1822 mg/kg ; 0,1555 $\mathrm{mg} / \mathrm{kg}$, sementara itu logam timah berturut-turut adalah $45,12 \mathrm{mg} / \mathrm{kg}$; $60,42 \mathrm{mg} / \mathrm{kg} ; 22,38 \mathrm{mg} / \mathrm{kg} ; 27,81$ mg.kg ; 45,65 mg/kg ; 42,39 $\mathrm{mg} / \mathrm{kg}$.berdasarkan ketetapan BPOM dan BSN pada tahun 2009, maka semua sampel minuman kemasan kaleng Layak dikonsumsi karena tidak melebihi ambang batas yang telah ditentukan.

3. kadar logam berat $\mathrm{Pb}$ dan $\mathrm{Sn}$ terkandung pada semua sampel minuman, dan jumlah cemaran paling tinggi terdapat pada sampel minuman yang diperoleh dari pasar tradisional dengan jenis minuman karbonasi.

4. Masa penyimpanan dan perlakuan terhadap sampel berpengaruh besar terhadap migrasi logam terhadap minuman didalamnya, semakin lama masa simpan semakin lama kontak logam yang terkandung pada kaleng terhadap minuman didalamnya.

\section{DAFTAR PUSTAKA}

Anonim, 2006, Penuntun Praktikum Kimia Anorganik III, Fakultas MIPA, Universitas Udayana : Denpasar,

Anonim. Laboratorium Teknik Analisis Radiometri Dan Spektrometri Serapan Atom Pusat Teknologi Nuklir Bahan Dan Radiomet.

Apriyantono, 1989, Analisis Pangan, Bandung: Departemen Pendidikan dan Kebudayaan . 
Direktorat Jendral Pendidikan Tinggi Pusat Antar Universitas: IPB

Ayu ning tyas, Irma Fitria (2014) : Kandungan Aluminium dalam Kaleng Bekas dan Pemanfaatannya dalam Pembuatan Tawas .http:http:///ojs.unud.ac.id//index .php//jchem//article//viewFile/ / 2806//1995,. Diakses 3 Januari 2014 Pukul 17:53 WIB.

Badan Standarisasi Nasional (1992). SNI 01-2896-1992:Cara uji cemaran logam. Jakarta: Badan Standarisasi Nasional.

Badan Standarisasi Nasionnal (1995). SNI 01-3719-1995 : Syarat mutu minuman sari buah.

Badan Standarisasi Nasional (2009). SNI 7387:2009:Batas maksimum cemaran logam berat dalam pangan. Jakarta: Badan Standarisai Nasional.

Balai Pemeriksaan Obat dan Makanan (2008). BPOM : Syarat mutu minuman berkarbonasi.

Cahyadi W. (2004) : Bahaya pencemaran Timbal pada makanandan minuman, Bandung: Fakultas Teknik Unpas Departemen Farmasi Pascasarjana ITB.

Christina P, Maria.2006.Petunjuk Praktikum Instrumentasi Kimia "Analisis Kesalahan Dalam Spektrometri Serapan Atom". Yogyakarta : STTN-BATAN.

Hendayana Sumar,1994.Kimia Analitik Instrumen.IKIP Semarang PRESS.

Joint FAO/WHO Expert Committee on Food Additives. (2003). Joint FAO/WHO Expert Committee on Food Additives, sixty-first meeting, 10-19 June 2003: Summaryandconclusions. $\quad 23$ Januari 2011 http://www.who.int/ipcs/food/je cfa/sumarries/en/summary_61.pd.

Julianti, E., dan Nurminah, M (2006). Teknologi Pengemasan. Medan : Universitas Sumatera Utara.

Kharisma, W. L. (2006). Analisis cemaran logam $\mathrm{Pb}, \mathrm{Cu}$, dan $\mathrm{Cd}$ dalam buah nanas (ananas comosus (L) Merr) kaleng pada batas kadaluarsa yang berbeda secara spektofotometri serapan atom. Jakarta : Fakultas Farmasi : Universitas Pancasila.

Notohadiprawiro, T (2006). Logam berat dalam pertanian. 24 Mei 2017.http:// soil.faperta.ugm.ac.id/ tj/1991/1993\%20loga.pdf.

Standar Nasional Indonesia (2009) : No. 3547-1-2009 tentang cemaran logam berat dalam makanan dan Minuman.

Standar Nasional Indonesia (2009) : No. 7387:2009 tentang logam berat timbal. Standar Nasional Indonesia (1995) : No. 01 -37191995 tentang syarat mutu minuman sari buah.

St, Hartini Djalil, Saifuddin, Zakaria, (2011) : Analisis kadar logam timbal pada pangan jajanan di SDN Aprilia, B, A. Faktor yang berhubungan dengan pemilihan makanan jajanan pada anak sekolah dasar [skripsi]. Semarang : Universitas Diponegoro.

Sumardi, 1996,Spektrofotometri Serapan Atom, Pusat Penelitian dan Pengembangan Kimia Terapan Lembaga Ilmu Pengetahuan Indonesia, Bandung

Suryati. 2011 Analisas kandungan logam berat $\mathrm{Pb}$ dan $\mathrm{Cu}$ dengan metode Spektofotometri Serapan Atom (SSA) terhadap ikan baung Universitas Islam Negri Sultan Syarif : Pekanbaru : Riau.

Vera (2011). Analisis Logam Berat Timbal (Pb), Timah (Sn), dan Kadmium (Cd) dalam Buah Lengkeng Kemasan Kaleng Secara Spektofotometri Serapan Atom. Jakarta : Fakultas Matematika dan Ilmu Pengetahuan Alam : FARMASI : Universitas Jakarta.

Vina Azis. 2007.Skripsi analisis kandungan $\mathrm{Sn}, \mathrm{Zn}, \mathrm{DAN} \mathrm{Pb}$ dalam susu kental manis kemasan kaleng secara spektofotometri serapan atom : Yogyakarta :UII 2528. 